\title{
EDITORIAL
}

\section{NEW PRIORITIES AND NEW DEVELOPMENTS IN HIGHER EDUCATION}

The issue to which this number is addressed is suitably broad to encompass even the most eclectic of tastes and interests. In effect, under the general rubric of "New Developments", it is possible to bring together practically all aspects and activities associated with higher education. It is useful, however, to make a distinction between "system adjustment" to change on the one hand and "new developments" on the other. The distinction, I would suggest, depends on whether the nature of the change involves simply a conjunctural response to shortterm factors or whether, by contrast, it brings fundamental alterations to the paradigm underlying higher education thereby causing us to revise our theories about that institution. In this context, "systems adjustment" may take place without altering the paradigm underlying higher education. "New developments", however, fall into the latter category. The question this raises is, "How does this distinction work in practice?" To take one example: the advent of the restricted entry policies in certain Western European countries during the earlier part of the 1970s did not impinge on the relationship between higher education and society. It was, in many respects, the reimposition of a function of selection which previously had been the role of the secondary school. And, if it affected students and Departments, it did not shed any new understanding of either one. Nor, for that matter, did it undermine theories regarding higher education as a general agency of human investment or of modernization.

The same cannot be said of those developments that have gathered apace from the start of the present decade. Certainly, many of the changes introduced in Western European systems started out as an adjustment to a deteriorating climate, both economically and, from the standpoint of higher education, financially as well. It is a moot point whether the drive to develop university/industry links, the pressure of governments on universities to concentrate more of their efforts on science and technology related areas - a trend which is not confined to Europe as Dr Olomalaiye's article on Nigeria shows - was a pragmatic adjustment or a response to an emerging new paradigm. Either way, it is, I think, clear that what began as "system adjustment" has gone beyond that point. Increasingly, higher education is being called upon to justify itself in market terms. Sometimes this can mean maximizing student output whilst holding resources constant. "Doing more with less." In others, the market ethic entails being sufficiently adaptable to meet rapidly new combinations of skills, competencies and qualifications that change in the economy throws up. In short, over the past five years a marked shift has taken place which sees higher education responsive less to individual demand than to the demands of the market. This is a delicate process, for in essence it involves a considerable reduction in what some authors see as the "internalist model of higher education." In other words, that the shaping of academic work, work practices and performance - the key elements in that much maligned phrase "academic autonomy" - are no longer solely under the control of academia. If such practices and performance are to be retained, they require formal justification in the light either of government priorities or what are held to be the "needs of industry."

Whether autonomy in higher education (which is after all a very relative term depending on differing national circumstances and condition) is today "negotiable", or "conditional" is a matter of detail and semantics. It is evident, nevertheless, that few areas of academic life are not under scrutiny, sometimes on the grounds of cost and efficiency, others on a more broad based principle that it is the formal obligation of the establishment to supply those skills the Nation or the market, as interpreted by government, demands.

None of this would be particularly controversial were it not for the fact that the application of the market paradigm, with its accompanying emphases on external competition between different establishments for students and resources and the rise of the so-called "entrepreneurial ethic", shows up the workings of higher education in a less than favourable light. As a result, this calls for changes in such areas as management - and thus participation structures, leadership - which involves established patterns of academic power, in addition to closer oversight by public authorities. Not only are these "developments" new in themselves, they are also "new" in the sense that they are surrounded by a powerful ideology which justifies a degree of public intervention and control that, ten years or so ago, would have summoned up the most strenuous opposition - an opposition all the more weighty for the fact that it could call upon established and well-grounded arguments for holding out against such intervention.

It is perhaps not surprising that relative shortage of resources, a shortage created either by other demands on the public budget or by demand for higher education outstripping the ability of a nation to uphold previous levels of financing, will entail a greater degree of "prioritization." At a broad level of generalization, there are two approaches involved. The first, arguably more pronounced in developing countries than in the industrial world and Western Europe in particular, can be seen as a species of withdrawal from an earlier theory that investment in higher education was a means of modernization relatively homogeneous across the different subject areas studied. Now the view is that some specific fields are more desirable than others, that they are more effective in achieving modernization than a general "shot gun" investment in institutions. Thus, the contribution of higher education to modernization has been narrowed in scope and definition. Consequently, one sees government intervention to 
favour particular fields or particular types of establishment specializing in such disciplines. The second approach, less uniformly dirigiste, but often with the same ends in view, is for government, at least in its public pronouncements, to withdraw the level of support from those areas not deemed to contribute directly to economic regeneration or, as an alternative tactic with much the same effect, to restrict the number of places in fields with a high risk of future unemployment. Withdrawal of support means, of course, that those wishing to survive must seek other sources of funding and to rearrange courses and programmes accordingly.

Some purists may see a slight paradox of a government intervening to ensure a better response to the "market." But this is to forget that, in theory at least, such intervention is seen as a temporary phase, a means to a vaster end of ensuring that higher education is fully aware of - and prepared for - continual change in the external environment. It is, surely, one of history's greater paradoxes that an ideology derived from neo-Liberal premisses should bring quite massive intervention of the state in its train. The repercussions of this in the Dutch context are explored in this issue by Dr Foppen.

But there is another perspective which reinforces the difference between "system adjustment" and "new developments", at least within the perspective of sociological theory. In Western Europe, the need in the national interest to "free up" higher education from an apparent over-reliance on central government has provided the state with a new "legitimacy" of action and intervention. This casts the theory of the "legitimacy crisis", developed by Habermas in the early seventies, in a rather different light. The notion of the "legitimacy crisis" derives from the belief that citizen groups in the course of the 1960s and 1970s showed increasing reluctance to permit government and administration to act on their behalf. Such groups preferred, rather, a more direct form of involvement in decision-making, which emerged in varied demands for "increased participation" or the right to "control one's own life" within industry, local affairs and, above all, in education. Faced with the determination of citizen pressure and interest groups based on a species of direct form of democracy, the credibility of the state was held to be diminished considerably.

"The new developments" - above all in higher education, the drive to develop the entrepreneurial paradigm, the stress placed on "leadership", management rationality and line accountability - suggest that the invocation of market forces in key social institutions of which higher education is the most obvious, act as a powerful dissolvant of the "legitimacy crisis". On the contrary, the invocation of "competition", of self-reliance and self-sufficiency have bestowed a "new legitimacy" upon government intervention - this despite the fact that of all key social institutions higher education has long been one in which "self rule" or autonomous decision-making has been the norm. The general thrust of "new developments" has, I would suggest, "re-legitimized" the role of the state.

Obviously, one cannot explore the full range of the consequences that flow from the seachange which has been gathering weight in higher education over the course of the decade. But there is sufficient evidence to show that "new developments" are in fact, as regards the repercussions they have upon some of the major theories that have governed our understanding of higher education, qualitatively different from "systems adjustment." Certainly, this is not the only interpretation. But it does have the convenience of distinguishing between short-term change and movements de longue durée. By bringing together the articles contained in our present issue, Higher Education Policy hopes to stimulate further the debate about the nature of present changes as well as the debate about the modifications it brings to the theory underlying the field of higher education.

Guy Neave 